\title{
AS AÇÕES COLETIVAS DE CONTROLE CONTRATUAL NO ÂMBITO DO CÓDIGO DE DEFESA DO CONSUMIDOR
}

Dennis Verbicaro*

SUMÁRIO: Introdução; 20 dirigismo contratual nas relações de consumo; 3 Ação declaratória de nulidade contratual: controle híbrido (concreto e abstrato) do contrato; 4 Ação constitutiva de revisão contratual com possibilidade de cumulação de pedidos condenatórios e/ou cominatórios; 5 Conclusão; Referências.

RESUMO: O presente artigo, por meio do método dedutivo e de pesquisa bibliográfica e jurisprudencial, visa destacar a relevância das ações coletivas de controle contratual para a proteção dos interesses transindividuais do consumidor, com especial destaque à ação declaratória de nulidade contratual e à ação constitutiva de revisão contratual com possibilidade de cumulação de pedidos condenatórios e/ou cominatórios. Nesse contexto, objetiva-se demonstrar que o dirigismo contratual previsto na lei 8.078/90 (Código de Defesa do Consumidor) influi na difusão de deveres éticos ao segmento empresarial, aperfeiçoa a aferição da vontade legítima do consumidor, garante o acesso à informação clara e qualificada quanto ao alcance das obrigações contratuais e, ainda, resguarda a satisfação do interesse social inerente à realização do negócio jurídico em si. Com base nessa constatação, a pesquisa conclui que as ações coletivas supracitadas propiciam o dirigismo contratual necessário nas atuais relações de consumo por meio de um modelo de instrumentalização processual sofisticado e eficiente.

PALAVRAS-CHAVE: Direito do consumidor; Processo coletivo; Dirigismo contratual; Práticas abusivas; Interesses transindividuais.

\section{CLASS ACTIONS OF CONTRACT CONTROL WITHIN THE CONTEXT OF THE CONSUMER CODE}

ABSTRACT: Employing the deductive method and bibliographical and jurisprudential research, current paper underscores the relevance of class actions in contract control for the protection of consumers' trans-individual interests. Declaratory action of contractual nullity and constitutive action of contractual revision will be underscored, coupled to the possibility of accumulation of condemnatory and com-

\footnotetext{
Doutor em Direito do Consumidor pela Universidade de Salamanca (Espanha). Docente da Graduação e do Programa de Pós-Graduação Stricto sensu da UFPA, Docente da Graduação e Especialização do CESUPA. É líder do Grupo de Pesquisa "Consumo e cidadania" (CNPQ). Procurador do Estado do Pará e Advogado.

E-mail: dennis@gavl.com.br
} 
minatory pleas. It will be proved that contractual dirigisme, contemplated in Law 8078/1990 (Consumers' Code), affects the diffusion of ethical duties for entrepreneurs, improves consumers' legitimate desires, warrants access for clear and quality information with regard to contract obligations and safeguards the satisfaction of social interests inherent to the compliance to juridical interactions. Research shows that class actions provide contractual dirigisme required in consumers' relationships through a model of sophisticated and efficient procedures.

KEY WORDS: Consumers' rights; Class action; Contract control; Abusive practices; Trans-individual interests.

\section{LAS ACCIONES COLECTIVAS DE CONTROL CONTRACTUAL EN EL ÁMBITO DEL CÓDIGO DE DEFENSA DEL CONSUMIDOR}

RESUMEN: En el presente artículo, por medio del método deductivo y de investigación bibliográfica y jurisprudencial, se tuvo por objetivo destacar la relevancia de las acciones colectivas de control contractual para la protección de los intereses transindividuales del consumidor, con especial hincapié a la acción declaratoria de nulidad contractual y a la acción constitutiva de revisión contractual con posibilidad de acumulación de pedidos condenatorios y/o conminatorios. En ese contexto, se objetiva demostrar que el dirigismo contractual previsto en la Ley 8.078/90 (Código de Defensa del Consumidor) influye en la difusión de deberes éticos al segmento empresarial, perfección la medición de la voluntad legítima del consumidor, garantiza el acceso a la información clara y calificada como al alcance de las obligaciones contractuales y, aún, resguarda la satisfacción del interés social inherente a la realización del negocio jurídico en sí. Con base en esa constatación, la investigación concluye que las acciones colectivas ya mencionadas propician el dirigismo contractual necesario en las actuales relaciones de consumo por intermedio de un modelo de instrumentalización procesual sofisticado y eficiente.

PALABRAS CLAVE: Derecho del consumidor; Proceso colectivo; Dirigismo contractual; Prácticas abusivas; Intereses transindividuales. 


\section{INTRODUÇÃO}

O Código de Defesa do Consumidor (lei 8.078/90) ${ }^{02}$ traz em seu capítulo processual, em especial no artigo 83, um tipo normativo aberto que favorece o reconhecimento de todas as espécies de ações capazes de legitimar a proteção material reconhecida ao longo da lei, ou seja, o comando normativo é amplo justamente para permitir o resgate do caráter instrumental do processo, ampliando as vias de participação política do consumidor no Judiciário, por meio de novos provimentos jurisdicionais, aperfeiçoando os já existentes, com ênfase nas tutelas de urgência e nas medidas de efetivação da decisão judicial, como as de natureza cautelar, dissuasórias e de constrição psicológica e patrimonial do réu.

Nesse particular, além das ações de responsabilidade civil e das executivas lato sensu das obrigações específicas de fazer e não fazer, as quais não serão objeto do presente artigo, há outras igualmente relevantes no âmbito da tutela coletiva das relações de consumo, destarte relacionadas ao controle do ambiente contratual, a saber: a ação declaratória de nulidade de cláusula contratual abusiva e a ação constitutiva de revisão contratual com possibilidade de cumulação de pedidos condenatórios e/ou cominatórios.

Com efeito, uma nova feição plural do Direito se sobressai a partir da ideia de solidariedade, melhor amparando os consumidores ante a massificação das práticas abusivas no mercado de consumo. Isto porque o paradigma processual tradicional, essencialmente individualista, não apresenta soluções eficazes face às demandas coletivas que se apresentam no contexto atual, razão pela qual a tutela coletiva do consumidor tem se mostrado cada vez mais necessária.

Em um mundo globalmente capitalizado, o indivíduo se tornou refém de seus impulsos materialistas que, sobrevalorizados pelos meios de publicidade e convencimento em massa, são vendidos como verdadeiras necessidades de consumo, supostamente fundamentais para o bem-estar físico e, sobretudo, psíquico, o que evidencia uma sociedade doente pelo consumo compulsivo e irresponsável pela perda crescente de sua autoestima cívica, ao não mais acreditar que pode ocupar os espaços políticos de deliberação criados pelo direito do consumidor em sua clara feição plural.

\footnotetext{
${ }^{02}$ BRASIL. Lei no 8.078 , de 11 de setembro de 1990. Código de Defesa do Consumidor. Diário Oficial [da] República Federativa do Brasil, Brasília, 12 set. 1990. Disponível em: < http://www.planalto.gov.br/ccivil_03/Leis/ L8078.htm > . Acesso em: 22 fev. 2018.
} 
Deste modo, as ações coletivas de controle contratual, objeto do presente artigo, possuem o condão de viabilizar a tutela difusa da categoria dos consumidores, a coletiva de seus grandes grupos determinados (coletivos em sentido estrito) ou por afinidade comum num caso concreto (acidentalmente coletivos/individuais homogêneos), assim como daqueles interesses individuais subjetivos de maneira plena.

Destarte, o presente artigo, por meio do método dedutivo e de pesquisa bibliográfica e jurisprudencial, visa destacar a relevância da defesa processual coletiva do consumidor para a proteção dos interesses transindividuais, a partir das ações específicas de controle contratual.

\section{O DIRIGISMO CONTRATUAL NAS RELAÇÕES DE CONSUMO}

Antes de se explicar o sentido e o alcance das ações coletivas de espectro contratual concebidas pelo Código de Defesa do Consumidor (CDC), convêm fazer algumas considerações acerca do dirigismo contratual do Estado em matéria de consumo.

O Estado, quando intervém num contrato através da lei, o faz para relativizar a vontade ou afastá-la quando presente a coação econômica. Essa novel possibilidade marca o instante temporal de uma revolução legislativa que modificou a passividade do direito nas relações privadas, quando se preocupava tão somente com os aspectos relativos à capacidade das partes, licitude do objeto e a forma prevista ou não proibida para o negócio jurídico. Desta forma,

[...] Na concepção clássica do contrato, o Estado - tanto o legislador como o julgador - deve interferir o mínimo possível na autonomia privada e, consequentemente, nos contratos. A atenção básica é com a capacidade das partes e com a eventual presença de vícios de consentimento (erro, dolo, coação). Demonstrada a capacidade dos sujeitos e inexistindo erro, dolo ou coação, restaria ao Estado fazer cumprir o acordo de vontades. O contrato é lei entre as partes: pacta sunt servanda..$^{03}$

Entretanto, isso era muito pouco, pois foi preciso adentrar no conteúdo da obrigação, analisar se o consumidor, quando manifestava sua vontade, o fazia por-

${ }^{03}$ BENJAMIN, Antonio Herman V.; MARQUES, Claudia Lima; BESSA, Leonardo Roscoe. Manual de Direito do Consumidor. 7.ed.rev., atual. e ampl. São Paulo: Revista dos Tribunais, 2016, p. 385. 
que precisava do bem de consumo e não porque houve uma liberdade contratual plena, ou seja, uma autonomia efetiva daquela vontade. Nesse sentido,

The law, once deeply influenced by individualistc logic, assumes itself in itsplural form. That is, now, from the perspective of solidarity, the law will consider the subject far beyond his individual condition, since it recognizes the existence of categories of people, according to the factual inequality. This imposes, as inevitable, the need for creating legal inequalities of treatment through a legitimate facto of discrimination, the vulnerability of the consumer to the holders of the means of production. ${ }^{04}$

E é reconhecendo essa vulnerabilidade e, em alguns casos, hipossuficiência do consumidor, que o $\mathrm{CDC}$ vai exercer seu dirigismo contratual, no sentido de identificar o contrato como uma prática que tem sido manipulada pelos fornecedores e acabou sendo adaptado para atender ao interesse exclusivo do segmento empresarial, com o intuito de reforçar a posição jurídica e econômica do fornecedor, pela diminuição de seus deveres na ordem jurídica, de excluir ou limitar suas responsabilidades e, assim, minimizar os riscos de futuras lides. Deste modo, o contrato passa a ter uma nova feição, pois, segundo Claudia Lima Marques, ${ }^{05}$

Hoje o contrato é o instrumento de circulação das riquezas da sociedade, hoje é também instrumento de proteção dos direitos fundamentais, realização dos paradigmas de qualidade, de segurança, de adequação dos serviços e produtos no mercado. O economicamente relevante é, na sociedade atual, prioritariamente, o imaterial, os fazeres e serviços complexos ou o bem imaterial. Destaque-se aqui que a crise da pós-modernidade no Direito advém da modificação dos bens economicamente relevantes se, na Idade Média, os bens economicamente relevantes eram os bens imóveis, na Idade Moderna, o bem móvel material, indiscutível que hoje, na Idade atual pós-moderna, valorizado está o bem móvel imaterial (software etc.) ou o desmaterializado "fazer" dos serviços, da comunicação, do lazer, da segurança, da educação, da saúde, do crédito. Se são estes bens imateriais e fazeres que são a riqueza atual, os contratos que autorizam e regulam a transferência dessas "riquezas" na sociedade também têm de mudar, evoluir do modelo tradicional de dar da compra e venda para modelos novos de serviços e dares complexos, adaptando-se a este desafio desmaterializante e plural "pós-moderno".

\footnotetext{
${ }_{04}$ VERBICARO, Dennis. Consumer new civil-instrumental identity based on the brazilian consumer policy. In: MARQUES, Claudia Lima; PEARSON, Gail; RAMOS, Fabiana (editors). Consumer protection: current challenges and perspectives. Porto Alegre: Orquestra, 2017, p. 126.

${ }^{05}$ MARQUES, Claudia Lima. Contratos no Código de Defesa do Consumidor: o novo regime das relações contratuais. 8. ed., rev., atual., e ampl. São Paulo: Revista dos Tribunais, 2016, p. 179.
} 
Para exemplificar, tem-se o contrato de adesão praticado nos estacionamentos comerciais, em que há nítida tentativa de exoneração de responsabilidade do fornecedor. É comum a utilização de dizeres do tipo "nós não nos responsabilizamos pelo veículo ou pelos pertences nele deixados”. Há uma relação contratual no momento em que o consumidor manifesta sua vontade de estacionar o veículo, mas estaria ele exercendo sua liberdade plena, pela simples adesão à vontade do fornecedor?

$\mathrm{Na}$ condição de mero aderente à vontade do fornecedor, por óbvio, não teria o consumidor condições de discutir a validade desta condição obrigacional, daí porque não se pode evocar o princípio tradicional do direito privado relativo à conservação do contrato, também denominado pacta sunt servanda.

Ora, há um desequilíbrio que é fático, econômico, e, em alguns casos, chega a ser até jurídico e técnico. Definitivamente, o direito não pode silenciar diante das novas formas de contratação em massa, do assédio de consumo e da técnica contratual do contrato de adesão que, a cada dia, manipula mais o consumidor, induzindo-o ao consumo desenfreado, bem como a aceitar a prevalência de princípios ultrapassados e individualistas do direito privado tradicional.

O CDC, quando apresenta essa nova roupagem para o contrato, estabelece uma técnica própria para a sua análise, não se limitando apenas ao aspecto da interpretação, mas também à aplicação da norma, na medida em que se tem um microssistema legal que estabelecerá princípios específicos, para que o equilíbrio da relação seja manifestado e alcançado não apenas sob o ponto de vista da integração das normas jurídicas. Como isso pode funcionar?

Há situações em que a lei não se refere expressamente a uma cláusula contratual que seja considerada abusiva, mas o CDC é apenas uma das normas componentes do ordenamento jurídico, existindo várias outras fontes formais do direito, que não apenas o exteriorizam, mas atribuem à norma jurídica sua validade obrigatória, ou seja, sua força vinculante. A lei é apenas uma dessas fontes.

$\mathrm{O}$ próprio $\mathrm{CDC}$, no art. $7^{\circ}$, caput, faz referência às fontes de integração do direito do consumidor, a saber: os princípios, costumes e etc. São essas fontes que irão suprir as eventuais lacunas da lei, eventuais omissões legislativas e que, de modo algum, vão inviabilizar a tutela consumerista, muito menos no ambiente contratual.

Em termos gerais, o contrato é uma autêntica prática comercial. Na verdade, é a prática comercial mais manipulada pelo fornecedor, porque como é ele quem re- 
dige o instrumento contratual terá melhores condições de estabelecer uma cláusula que irá desestimular o consumidor de reclamar pelo seu direito.

Por exemplo, quando o fornecedor informa que não devolve as parcelas pagas em caso de desistência do contrato, tem-se aí cláusula opressiva, que impõe ao consumidor desvantagem exagerada, aproveitando-se de sua vulnerabilidade e de sua deficiência de conhecimento. Esse tipo de estimulação será considerado nulo de pleno direito pelo inciso I do artigo 51 do CDC, estando, portanto, fora do âmbito de disposição do consumidor.

Todavia, um leigo ou um consumidor que não receba a orientação jurídica adequada acabará acreditando que realmente não poderá reclamar e que por ter dado causa ao atraso no pagamento das prestações, seria lícito ao fornecedor retomar o bem, cobrar o valor residual do contrato, devendo aceitar passivamente sua inclusão no cadastro de inadimplentes, sem receber nada de volta do que foi pago, independentemente se já havia despendido no pagamento de quase a totalidade do valor do bem.

Decididamente, esse tipo de procedimento não poderá ser analisado pelo Código Civil ${ }^{06}$, porque ao Estado compete definir um tratamento jurídico diferenciado ao consumidor, o que não se verifica nos tradicionais diplomas privados. Embora já tenha havido grande evolução a partir do Código Civil, que entrou em vigor em janeiro de 2003, recepcionando o princípio da boa-fé, a transparência pré-contratual (arts. 421 e ss), contudo, ainda é pouco para se comparar ao nível de eficiência do $\mathrm{CDC}$, que apesar dos 27 anos de vigência, apresenta à coletividade de consumidores uma proteção muito mais ampla, consistente e melhor sistematizada, sobretudo para o melhor controle da técnica da adesão.

Nesse sentido, embora se reconheça o contrato de adesão como uma técnica de contratação em massa aparentemente válida, comum na relação de consumo, não se permitirá ao fornecedor a livre estipulação das condições contratuais, até porque se compreende que, como o contrato de adesão é um contrato em que não há fase pré-negocial, o consumidor não terá condições de exercer sua liberdade de escolha ante o caráter uniforme da oferta e, em alguns casos, haverá dificuldade de optar por outro contratante, sobretudo no caso dos serviços públicos prestados em

\footnotetext{
${ }^{06}$ BRASIL. Lei $\mathrm{n}^{0} 10.406$, de 10 de janeiro de 2002. Código Civil. Diário Oficial [da] República Federativa do Brasil, Brasília, 11 jan. 2002. Disponível em: < http://www.planalto.gov.br/CCivil_03/leis/2002/L10406.htm>. Acesso em: 22 fev. 2018.
} 
regime de monopólio. Assim, segundo Marques ${ }^{07}$,

No novo modelo contratual há uma revalorização da palavra empregada e do risco profissional aliada a uma grande censura intervencionista do Estado quanto ao conteúdo do contrato. É um acompanhar mais atento para o desenvolvimento da prestação, um valorizar da informação e da confiança despertadas. Alguns denominam o novo modelo de renascimento da autonomia da vontade protegida. $\mathrm{O}$ esforço deve ser agora para garantir uma proteção da vontade dos mais fracos, como os consumidores. Garantir uma autonomia real da vontade do contratante mais fraco, uma vontade protegida pelo Direito, vontade liberta das pressões e dos desejos impostos pela publicidade e por outros métodos agressivos de venda é o objetivo.

Destarte, é prudente que a lei estabeleça parâmetros para que o contrato redigido sob a forma da adesão possa ser reconhecido como negócio jurídico válido. $\mathrm{O}$ fato de o consumidor manifestar o seu consentimento, aderindo à vontade do fornecedor, não necessariamente expressa a ideia de liberdade contratual, assemelhando-se mais a uma declaração unilateral de vontade, em que o consumidor adere por falta de opção e por necessidade.

A técnica da adesão, portanto, produz instrumentos contratuais que terão sua validade e eficácia condicionadas aos parâmetros normativos do CDC, que reconhece o caráter vexatório e opressivo de certas cláusulas contratuais ou condições gerais de contratação e, por essa razão, são retiradas do âmbito de disposição do consumidor, por meio do dirigismo contratual implementado pela lei.

Isso significa dizer que, por mais que estejam presentes os elementos essenciais do negócio jurídico, tais como capacidade das partes, objeto lícito e possível, forma prescrita ou não defesa em lei, o contrato será analisado em seu conteúdo, de tal modo a se avaliar se as obrigações nele estabelecidas são compatíveis com a boa fé, sua função social em relação às expectativas do consumidor, assim como se atende à ideia de equidade.

Nessa linha de raciocínio, o art. 51 do CDC estabelece um rol exemplificativo de cláusulas consideradas abusivas. Isso significa dizer que o artigo apresentará apenas exemplos de cláusulas que poderão ser declaradas nulas de pleno direito, admitindo-se, naturalmente, que podem existir outras, desafiando a atuação administrativa da Secretaria Nacional de Direito Econômico, que cedeu espaço ao Departamento de Proteção e Defesa do Consumidor-DPDC, hoje substituído pela $\overline{{ }^{07} \text { MARQUES, 2016, p. }} 180$. 
Secretaria Nacional do Consumidor, subordinada ao Ministério da Justiça, que edita portarias e expede atos normativos que podem aditar o alcance daquele rol.

Quando o legislador utiliza a expressão "dentre outras" pretende que aquelas hipóteses descritas no artigo 51 funcionem apenas como referência ilustrativa das condições abusivas comuns nos contratos. Isso não impede que o operador do direito venha a enquadrar outras cláusulas contratuais, até porque, no próprio dispositivo, há outros tipos abertos, ou seja, outras hipóteses legais bastante genéricas, para justamente ampliar o âmbito da tutela, como no exemplo das referências constantes nos incisos IV e XV, sem falar do conceito de vantagem exagerada constante no parágrafo $1^{\circ}$ do mesmo artigo 51 , que dá a exata dimensão do alcance aberto do dirigismo contratual.

Vê-se, claramente, o alto grau de aprimoramento da tutela contratual do consumidor, a partir do rompimento com o nocivo individualismo do direito privado tradicional, o que tornou esse capítulo da lei um espaço fértil para inovações materiais e processuais, que objetivavam maior aproximação com a ideia de solidariedade, sendo a ação de nulidade contratual uma consequência natural desse processo.

\section{AÇÃO DECLARATÓRIA DE NULIDADE CONTRATUAL: CONTROLE HÍBRIDO (CONCRETO E ABSTRATO) DO CONTRATO}

Esta ação revisional é mais uma inovação do CDC, pois se conferiu ao Ministério Público a legitimidade exclusiva para exercer o dirigismo contratual em abstrato no âmbito das relações de consumo, ou seja, o $\S 4^{\circ}$ do artigo 51 prevê a possibilidade de qualquer consumidor ou entidade que o represente requerer ao órgão ministerial a propositura de ação declaratória de nulidade contratual.

Haveria, nesse dispositivo legal, um controle híbrido em que se tutelariam, simultaneamente, interesses coletivos no plano concreto (coletivos em sentido estrito e individuais homogêneos) e no plano abstrato (difusos).

Numa análise preliminar, se poderia presumir uma natural incompatibilidade entre o controle difuso do CDC, pautado em relações factuais, com o dirigismo contratual. Todavia, a ideia aqui defendida diz respeito a um provimento jurisdicional que, reconhecendo a nulidade da cláusula ou condição geral de contratação, a retire do âmbito de disposição do aderente não apenas em relação aos contratos já firmados, mas também em relação aos contratos futuros, ou seja, para os consumi- 
dores potencialmente expostos a uma modalidade de contratação irregular.

Neste caso, embora o dispositivo legal se refira apenas à nulidade de cláusula contratual, o que pressupõe a ideia de contrato em concreto, não se concebe que as condições gerais de contratação $0^{08}$, justamente por seu caráter essencialmente difuso, sejam excluídas do âmbito de incidência dessa importante ferramenta de controle abstrato, daí porque se preferiu denominar a ação como declaratória de nulidade contratual e não ação de nulidade de cláusula contratual, o que implicaria na restrição do conceito.

Diz-se um "dirigismo híbrido", uma vez que a intenção do legislador, nesse caso, ao especificar o controle da abusividade de cláusula contratual em dispositivo específico, foi permitir que o Ministério Público pudesse levar a efeito também a proteção difusa dos consumidores potencialmente expostos àquelas condições desvantajosas, o que não exclui a legitimidade ampla e irrestrita do próprio Ministério Público e dos demais legitimados coletivos para a propositura de ações acerca de contratos em concreto de alcance determinado, pois se assim não o fosse, o $\S 4^{0}$ do artigo 51 seria uma referência legal meramente enfática da tutela contratual do consumidor por parte do órgão ministerial, o que não teria grande utilidade prática na sistemática do código.

A intenção legislativa, nesse caso, foi criar uma nova espécie de ação coletiva, justamente para garantir a extensão dos efeitos da tutela difusa, prevista no artigo 29 do CDC, por meio do conceito de consumidor exposto no ambiente contratual, a rigor frequentado apenas por titulares de interesses coletivos em sentido estrito, individuais homogêneos e, naturalmente, individuais subjetivos.

Também, não seria razoável e processualmente vantajoso que, em situações concretas, onde houvesse a nulidade de cláusulas abusivas, o que quase sempre traz a reboque outras consequências danosas ao consumidor, se propusesse apenas ação de natureza declaratória, quando se esperaria dos legitimados que reclamassem outros tipos de provimento jurisdicional, como os constitutivos (ações revisionais), condenatórios ou até mesmo cominatórios.

Desse modo, como a natureza da ação é meramente declaratória, um dos objetivos lógicos seria também o controle difuso da abusividade da cláusula, sobretudo nas hipóteses de dano potencial, justamente para que a declaração de nulidade tenha efeito erga omnes e, com isso, seja possível preservar a manifestação de vonta-

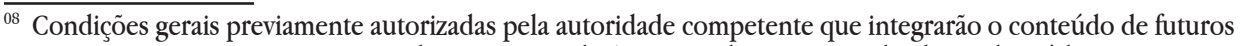
contratos, como ocorre, por exemplo, com as condições gerais dos contratos de planos de saúde, previamente aprovadas pela Agência Nacional de Saúde Suplementar (ANS) e que, num segundo momento, serão inseridas nos contratos padrão para o serviço privado de saúde. 
de de consumidores indeterminados e que poderiam se habilitar aos efeitos daquele contrato, ou condição geral de contratação.

Instituto semelhante é observado na Espanha, por meio das acciones colectivas de cesación, retratación y declarativas de condiciones generales. ${ }^{09}$

Nas duas primeiras, sua finalidade seria de fazer cessar o uso de recomendação de condições gerais que sejam contrárias ao disposto na legislação de consumo, possuindo a ação coletiva de cessação, também, o objetivo de viabilizar um provimento jurisdicional condenatório em que o demandado elimine as condições gerais reputadas como nulas e se abstenha no futuro de utilizá-las, à semelhança da tutela inibitória do direito brasileiro, de natureza executiva lato sensu e prevista no artigo 84 do CDC.

As acciones de cesación do direito espanhol são consequências da unidade normativa em matéria de consumo no âmbito da União Europeia e têm como foco o controle das práticas comerciais ilícitas de alcance transnacional. ${ }^{10}$

Estas ações podem ser manejadas pelas associações ou corporações de empresários, profissionais liberais e agricultores que tenham a defesa de seus membros prevista previamente em seus estatutos, as Câmaras de Comércio, Indústria e Navegação, as associações representativas de consumidores e usuários legalmente constituídas e com igual previsão estatutária para a defesa coletiva do consumidor, os colégios profissionais (Ex: OAB), como também o Ministério Público que, diferentemente do que ocorre no direito brasileiro, não é o legitimado exclusivo para o controle coletivo em abstrato do contrato, o que favorece a maior amplitude da tutela.

Estas ações coletivas podem ser dirigidas conjuntamente em face de vários fornecedores do mesmo setor econômico ou contra várias de suas associações que utilizem ou recomendem a utilização de condições gerais que se considerem nulas. ${ }^{11}$

Ademais, em que pese la acción de cesación, inicialmente prevista apenas na Ley de Condiciones Generales de la Contratación, ter sido concebida apenas para a discussão em abstrato de eventuais nulidades nas condições gerais de contratação, hoje, tem seu espectro de atuação elastecido pela forte influência das Diretivas da União Europeia, para a proteção dos interesses coletivos dos consumidores em qualquer matéria, não apenas no que dista ao controle contratual, o que também

\footnotetext{
${ }^{09}$ REYES LÓPEZ, Maria José. Manual de Derecho Privado de Consumo. Madrid: La Ley, 2009, p. 216.

${ }^{10}$ BUJOSA VADELL, Lorenzo. Coautoria en Manual Básico de Protección de los Consumidores y Usuários. Salamanca: Caja Duero, 2006, p. 251-252.

${ }^{11}$ BUJOSA VADELL, 2006, p. 217-218.
} 
ocorreu pelo advento da Ley 39/2002, que alterou a Ley General de Defensa de Consumidores Y Usuários. ${ }^{12}$

Neste particular, é conveniente observar, a partir do direito espanhol, que a lógica do associativismo, para efeito do debate político entre os sujeitos da relação de consumo, como também para instrumentalização das ações coletivas, atinge não apenas os consumidores, como também os fornecedores, porquanto terão melhores condições de articulação junto aos órgãos estatais, como também para se defender em juízo, experiência essa que poderia ser importada para o Brasil, por meio de um maior engajamento cívico da sociedade civil por meio das Associações Representativas, seja no exercício de sua legitimação extraordinária para as ações coletivas, seja pelo poder normativo autônomo de celebração de convenções coletivas de consumo nos termos do artigo 107 do CDC.

\section{AÇÃO CONSTITUTIVA DE REVISÃO CONTRATUAL COM POSSIBILIDADE DE CUMULAÇÃO DE PEDIDOS CONDENATÓRIOS E/OU COMINATÓRIOS}

Como referido anteriormente, a ação declaratória de nulidade contratual terá alcance limitado ao controle difuso do consumidor, o que não elide a possibilidade de se requerer, em qualquer outra modalidade de ação coletiva ou individual, um pedido declaratório de nulidade de cláusula contratual cumulativamente com outros pedidos. De acordo com Benjamin, Marques e Bessa ${ }^{13}$, na ação coletiva,

O objeto da ação é exteriorizado pela causa de pedir e pela tutela requerida, que pode se desdobrar em múltiplos pedidos e formulações: simples, cumulado, sucessivo, alternativo, eventual. Um mesmo fato pode ensejar diferentes pretensões jurídicas, que por seu turno podem ser jurisdicionalizadas por meio de uma única ação coletiva com cumulação de pedidos ou, alternativamente, por intermédio de várias ações coletivas.

Todavia, a razão da especificidade legal da ação declaratória acima referida precisa ser destacada, porquanto além do alcance limitado, há a legitimidade ex-

${ }^{12}$ SÁNCHEZ BARRIOS, Maria Inmaculada. El ejercicio de la "acción de cesación" en defensa de los consumidores y usuários. In: SÁNCHEZ BARRIOS, Maria Inmaculada (direción). Estudios sobre consumo. Valencia: Tirant lo Blanch, 2012, p. 526.

13 BENJAMIN; MARQUES; BESSA, 2016, p. 527, grifo do autor. 
traordinária exclusiva ${ }^{14}$ do Ministério Público, o que destoa do padrão de todas as demais ações coletivas admitidas no direito consumerista brasileiro, quando a legitimidade será extraordinária, concorrente, disjuntiva e não exclusiva.

Inicialmente, faz-se mister ressaltar a possibilidade do uso da ação revisional para rever cláusulas contratuais abusivas, como, por exemplo, ocorre nos contratos bancários em que houve grandes debates no Judiciário brasileiro sobre o tema, que embora já se encontre sumulado (súmula 297, do Superior Tribunal de Justiça-STJ e ADI 2591), está longe de estar pacificado.

Não é por outro motivo que o STJ sinaliza a possibilidade de aplicação às instituições financeiras das disposições do Código de Defesa do Consumidor, no que pertine à possibilidade de revisão dos contratos, conforme cada situação específica. $^{15}$

Da mesma forma, apenas para ilustrar a amplitude da proteção legal do consumidor, podemos enquadrar o procedimento do réu de inserir cláusulas abusivas no contrato com intuito de ludibriar o consumidor, também, como prática abusiva, prevista no artigo 39, IV e 51, parágrafo $1^{\circ}$ do CDC.

No magistério de Herman Benjamin ${ }^{16}$, prática abusiva é a desconformidade com os padrões mercadológicos de boa conduta em relação ao consumidor. Prossegue, afirmando, que a prática abusiva no Código é apenas aquela que, de modo direto e no sentido vertical da relação de consumo (do fornecedor ao consumidor), afeta o bem-estar do consumidor.

As práticas abusivas nem sempre se mostram como atividades enganosas, pois em outras hipóteses simplesmente dão causa a danos substanciais contra o consumidor. Manifestam-se por meio de uma série de atividades, pré e pós-contratuais, assim como propriamente contratuais.

Neste particular, tanto o controle pré-contratual (oferta e publicidade), como o contratual buscam preservar os princípios da boa-fé, função social e equilíbrio.

De bom alvitre, também, destacar que, no bojo das ações coletivas, há nítida

\footnotetext{
${ }^{14}$ Exceção à regra da legitimidade extraordinária, concorrente, disjuntiva e não exclusiva prevista nos artigos $5^{\circ}$ da Lei de Ação Civil Pública (ACP) e 82 do CDC, prevista para todas as demais espécies de ações coletivas no âmbito das relações de consumo, conforme já explicitado no tópico acerca de legitimação ativa e passiva nas ações coletivas.

${ }^{15}$ Cf. REsp 468281/RS; Ministro Aldir Passarinho Junior; Data de publicação: 24/02/2003 e AgRg no Ag 821115/ SC; Ministra Nancy Andrighi; Data de publicação: 28/05/2007.

${ }^{16}$ BENJAMIN, Antônio Herman; MARQUES, Claudia Lima. Extrato do Relatório-Geral da Comissão de Juristas do Senado Federal para atualização do Código de Defesa do Consumidor. Revista de Direito do Consumidor, São Paulo, ano 23, vol. 93, maio-junho/2014, p. 307.
} 
preocupação com a observância das denominadas cláusulas gerais estatuídas pelo Código Civil, tais como a boa-fé objetiva e a função social do contrato, originariamente apresentadas ao ordenamento jurídico brasileiro pelo CDC.

Com a inclusão destas cláusulas gerais no Código Civil, o legislador ordinário possibilitou ao magistrado a solução de cada caso concreto, levando-se em conta não somente conceitos e princípios contidos no direito privado, mas também de outros sistemas, como os expressos na Constituição Federal e nas inúmeras leis esparsas, estas últimas modernamente denominadas de microssistemas.

Em verdade, o enunciado das cláusulas gerais, ao invés de traçar pontualmente a hipótese e as suas consequências, é desenhado como uma moldura, permitindo, pela vagueza semântica que caracteriza os seus termos, a incorporação de princípios, diretrizes e máximas de conduta.

A boa-fé objetiva, como princípio geral do direito do consumidor, exprime um dever de conduta fundado na honestidade, na retidão, na lealdade, e, principalmente, na consideração para com os interesses do outro, em sintonia com o ideal de solidariedade.

$\mathrm{Na}$ seara contratual, a boa-fé objetiva ainda concorre para determinar o comportamento devido pelas partes contratantes, funcionando como um limite ao exercício de direitos subjetivos.

Estabelece o art. 422 do Código Civil de 2002: "Os contratantes são obrigados a guardar, assim na conclusão do contrato, como em sua execução, os princípios de probidade e boa-fé.".

Com efeito, da boa-fé nascem, mesmo na ausência de regra legal ou previsão contratual específica, os deveres de proteção, cuidado, previdência e segurança com a pessoa e os bens da contraparte, de colaboração para o correto adimplemento do contrato, de informação, aviso e aconselhamento, que devem permear não só as fases de conclusão e execução dos contratos, mas também as fases pré e pós-contratuais. Consistem, em suma, na adoção de determinados comportamentos, impostos pela boa-fé em vista do fim do contrato, dada a relação de confiança que o contrato fundamenta, ou seja, comportamentos variáveis de acordo com as circunstâncias concretas da contratação, que deverão ser definidas pelo Poder Judiciário quando da análise do caso concreto.

Assim, cabe ao magistrado, no caso concreto, a aplicação da cláusula geral de boa-fé objetiva, concretizando o enunciado do art. 422 do Código Civil por meio da aplicação de preceitos, máximas de conduta e princípios presentes não só no 
próprio Código Civil, mas também em outros diplomas legais, inclusive na própria Constituição Federal.

Cita-se, ainda, como cláusula geral prevista no código civil pátrio a função social do contrato.

Dispõe o art. 421 do Código Civil brasileiro: "A liberdade de contratar será exercida em razão e nos limites da função social do contrato.".

A atribuição de uma função social ao contrato é reflexo do fenômeno verificado nas últimas décadas de funcionalização dos direitos subjetivos.

Em razão desse fenômeno, o poder subjetivo de contratar e a forma de seu exercício são afetados pela funcionalização, que indica a atribuição de um poder, tendo em vista certa finalidade, ou a atribuição de um poder, que se desdobra como dever, posto que concedido para a satisfação de interesses não meramente próprios ou individuais, mas de interesses alheios ou metaindividuais.

A função social do contrato foi inserida no Código Civil de 2002 não como mero princípio, mas, assim como a boa-fé objetiva, como verdadeira cláusula geral, com a função precípua de restringir a liberdade contratual absoluta, típica das codificações do século XIX, que, como é cediço, inspiraram o legislador do revogado Código Civil de 1916.

Assim, de indiscutível mérito foi a inclusão da cláusula geral da função social do contrato no novo Código Civil, haja vista que a liberdade de contratar, modernamente, deixou de ser um direito subjetivo absoluto. Muito pelo contrário, o contrato, como instrumento de circulação de riqueza, interessa não só a uma pessoa ou a um grupo delas, mas a toda coletividade.

Nem pode o réu, como matéria de defesa, invocar a irrestrita observância ao princípio da autonomia da vontade (pacta sunt servanda), porquanto esta, diante da onerosidade excessiva do contrato, deve ceder em face da cláusula rebus sic stantibus, bem como em razão da sua abusividade.

Foi pensando nisso que o CDC apresenta um rol de normas imperativas que proíbem a utilização de qualquer cláusula abusiva, definida como a que assegure vantagens unilaterais ou exageradas para o fornecedor de bens e serviços, ou que seja incompatível com a boa-fé e a equidade.

O artigo 51, incisos IV, XV e o parágrafo $1^{\circ}$, I, II e III do CDC são bastante claros ao propagar o dirigismo contratual, seja por meio de referências específicas, ou mesmo pela presença de tipos normativos abertos.

Além disso, na linha do magistério jurisprudencial do Superior Tribunal de Justiça, o princípio pacta sunt servanda deve ser interpretado de acordo com a 
realidade socioeconômica. A interpretação literal da lei cede espaço à realização do justo. Neste sentido, conferir:

Ementa: Resp - Civil - Locação - Teoria Da Imprevisão - O Antigo Pacta Sunt Servanda - Não Encerra Princípio Absoluto. Urge Conjugá -Lo Com A Justiça. O Contrato, Assim, Pode Ser Objeto De Revisão. Eficácia Da Clausula Rebus Sic Stantibus. ${ }^{17}$

Ementa: RESP - CIVIL - LOCAÇÃO - REVISIONAL - ACORDO DAS PARTES - O princípio - "pacta sunt servanda" - deve ser interpretado de acordo com a realidade sócio-econômica. A interpretação literal da lei cede espaço à realização do justo. $\mathrm{O}$ magistrado deve ser o crítico da lei e do fato social. A cláusula "rebus sic stantibus" cumpre ser considerada para o preço não acarretar prejuízo para um dos contratantes. A lei de locação fixou prazo para a revisão do valor do aluguel. Todavia, se o período, mercê da instabilidade econômica, provocar dano a uma das partes, deve ser desconsiderado. No caso dos autos, restara comprovado que o último reajuste do preço ficara bem abaixo do valor real. Cabível, por isso, revisá-lo judicialmente. ${ }^{18}$

Dessa maneira, a vontade das partes manifestada livremente no contrato não é mais o fator decisivo para o direito, uma vez que as normas do Código instituem novos valores superiores, como o equilíbrio e a boa-fé nas relações consumeristas, razão pela qual os artigos $6^{\circ}$, V e 47 do CDC instituíram, como direito do consumidor, a modificação das cláusulas contratuais e que estas serão interpretadas de maneira mais favorável ao consumidor, demonstrando, portanto, que não apenas a nulidade absoluta serviria como sanção, mas também que seria possível ao magistrado, quando provocado, modificar o conteúdo negocial, o que nas ações coletivas terá grande impacto no modo de comportamento dos agentes econômicos do mercado, seja pela maior participação do consumidor na revisão dos abusos, seja modulando os compromissos éticos do fornecedor. ${ }^{19}$

Assim, de acordo com Marques ${ }^{20}$,

[...] formado o vínculo contratual de consumo, o novo direito dos contratos opta por proteger não só a vontade das partes, mas tam-

${ }_{17}$ BRASIL. Superior Tribunal de Justiça. Recurso especial no 98673/SP, Relator: Min. Luiz Vicente Cernicchiaro, 1997. Jusbrasil. Disponível em: <https://stj.jusbrasil.com.br/jurisprudencia/534682/recurso-especial-resp98673-sp-1996-0038483-5> . Acesso em: 10 mar. 2017.

${ }^{18}$ BRASIL. Superior Tribunal de Justiça. Recurso especial no 177018/MG, Relator: Min. Luiz Vicente Cernicchiaro, 1998. Jusbrasil. Disponível em: < https://stj.jusbrasil.com.br/jurisprudencia/486478/recurso-especial-resp177018-mg-1998-0041148-8 > . Acesso em: 10 mar. 2017.

19 MARQUES, Claudia Lima. Os contratos no Código de Defesa do Consumidor. 3.ed. São Paulo: Revista dos Tribunais, 1999, p. 906.

${ }^{20}$ MARQUES, 1999, p. 908. 
bém os legítimos interesses e expectativas dos consumidores. O princípio da equidade, do equilíbrio contratual e cogente; a lei brasileira, não exige que a cláusula abusiva tenha sido incluída no contrato por 'abuso do poderio econômico' do fornecedor [...] ao contrário, o CDC sanciona e afasta apenas o resultado, o desequilíbrio, não exige ato reprovável do fornecedor; a cláusula pode ter sido aceita conscientemente pelo consumidor, mas traz vantagem excessiva para o fornecedor, se é abusiva, o resultado é contrário à ordem pública, contrário às novas normas de ordem pública de proteção do CDC, e a autonomia da vontade não prevalecerá.

As normas do CDC são de ordem pública e origem constitucional, de onde se retira que a nulidade de pleno direito discutida nas ações coletivas deve ser interpretada como nulidade absoluta cominada (art. 166, VI e VII do CC/2002), proibindo o CDC expressamente estes abusos (arts. 51 e 53). A jurisprudência brasileira, em especial o STJ, já pacificou a questão, pois considerou que é possível ao Judiciário atuar ex officio na proteção dos consumidores para controle das cláusulas abusivas em contratos de consumo. ${ }^{21}$

As cláusulas abusivas identificadas nas listas dos arts. 51 e 53 do CDC, relativas aos contratos de compra e venda a prazo, implicam em nulidade absoluta. Conforme o STj ${ }^{22}$ tem-se,

Direito civil - Promessa de compra e venda - Extinção - Iniciativa do promissário comprador - Perda das parcelas pagas - Cláusula abusiva - Código de Defesa do Consumidor - Norma de ordem pública - Arts. 51, IV e 53 - derrogação da liberdade contratual - redução - Possibilidade - Recurso desacolhido. [...] II - O caráter de norma pública atribuído ao Código de Defesa do Consumidor derroga a liberdade contratual para ajustá-la aos parâmetros da lei, impondose a redução da quantia a ser retida pela promitente vendedora a patamar razoável, ainda que a cláusula tenha sido celebrada de modo irretratável e irrevogável. [...].

Contudo, cabe destacar que o art. $6^{\circ}, \mathrm{V}$ do $\mathrm{CDC}$ institui, como direito do consumidor, a modificação das cláusulas contratuais, demonstrando, portanto, que não apenas a nulidade absoluta serviria como sanção, mas também que seria possível ao magistrado modificar o conteúdo negocial.

Desta feita, o art. $6^{\circ}, \mathrm{V}$ do CDC apresenta uma exceção no sistema de nuli-

${ }^{21}$ Ibid., p. 908-909.

${ }^{22}$ BRASIL. Superior Tribunal de Justiça. Recurso especial no 292942/MG, Relator: Min. Sálvio de Figueiredo Teixeira, 2001. Jusbrasil. Disponível em: < https://stj.jusbrasil.com.br/jurisprudencia/313473/recurso-especial -resp-292942-mg-2000-0133343-7> . Acesso em: 10 mar. 2017. 
dade absoluta das cláusulas, proporcionando ao magistrado a faculdade de revisar ou "modificar", mediante solicitação do consumidor, "as cláusulas contratuais que estabeleçam prestações desproporcionais" ou que sejam "excessivamente onerosas" para o mesmo, em razão de fatos supervenientes.

O próprio Código Civil estabelece no artigo art. 478, que nos contratos de execução continuada ou diferida, se a prestação de uma das partes se tornar excessivamente onerosa, com extrema vantagem para a outra, em virtude de acontecimentos extraordinários e imprevisíveis, poderá o devedor pedir a resolução do contrato. Os efeitos da sentença que a decretar retroagirão à data da citação.

No artigo 479, por sua vez, ficou estabelecido que a resolução poderá ser evitada, oferecendo-se o réu a possibilidade de modificar equitativamente as condições do contrato.

Desta forma, considerando que o fornecedor, de um modo geral, impõe ao consumidor prestações desproporcionais, desequilíbrio entre direitos e obrigações e, portanto, cria lesão, sobretudo no ambiente contratual, não há dúvida que o manejo da ação de nulidade contratual, no exercício do controle coletivo abstrato do CDC, será uma ferramenta de grande valia no processo constante de harmonização de interesses contrapostos nas relações de consumo, rompendo com a premissa equivocada de que o controle coletivo do contrato no CDC se resume aos interesses metaindividuais concretos (individuais homogêneos e coletivos em sentido estrito).

Neste particular, o pedido constitutivo de rescisão contratual poderá ser cumulado com pedido condenatório por dano moral coletivo, cujo reconhecimento é controverso, não apenas nesta espécie de ação coletiva, como em todas as demais ações para a defesa de interesses indivisíveis.

Argumentos em sentido contrário a esse tipo de reparação moral a sujeitos coletivos já vêm encontrando eco na jurisprudência do Superior Tribunal de Justiça, quando se refuta a possibilidade da coletividade se vincular à noção de dor, de sofrimento psíquico, ambos de caráter individual. Isso seria incompatível com a noção de transindividualidade (indeterminabilidade do sujeito passivo e indivisibilidade da ofensa e da reparação). ${ }^{23}$

A despeito das controvérsias acima, a jurisprudência se mostra ainda "aberta” à construção desse novo conceito jurídico de dano moral coletivo, o que alimenta a expectativa da coletividade de consumidores de vislumbrar, por meio de uma condenação a esse título, não uma compensação econômica, o que seria inviável em razão da própria impossibilidade de fruição individual do objeto da tutela difusa e

${ }^{23}$ DIDIER JUNIOR, Fredie; ZANETI JUNIOR, Hermes. Curso de Direito Processual Civil: processo coletivo. 4.ed. Salvador: JusPodium, 2009, p. 295. 
coletiva em sentido estrito, mas, pelo menos, uma condenação de caráter pedagógico no infrator, para evitar a recorrência da conduta ilícita.

Nesse particular, adequada se mostra a compreensão de que o legislador, ao reconhecer os direitos da solidariedade a partir de novas categorias de interesses transindividuais, conferiu em favor da coletividade valores extrapatrimoniais que ultrapassavam a noção individualista de "pessoa humana", amplamente utilizada para justificar o abalo moral, mas que, no âmbito coletivo, teria o dano um caráter majoritariamente punitivo e, secundariamente, compensatório. ${ }^{24}$

Quanto à interpretação do dano extrapatrimonial coletivo pelos tribunais, há problema na fundamentação das decisões e a questão assume maior relevo em face da precariedade na motivação das decisões judiciais, haja vista que os julgados tratam de forma unitária quantias atribuídas a títulos inteiramente diversos, a partir de fatos e argumentos distintos, tornando impossível distinguir-se a parcela concedida a título de compensação do dano daquela que se pretende atribuir a título de punição ao ofensor. Essa imprevisibilidade jurídica inviabiliza o controle da racionalidade da sentença. Em outras palavras, haveria um estreito limite entre as ideias de arbitramento e arbitrariedade. ${ }^{25}$

A interpretação judicial tem esbarrado na dificuldade em estabelecer uma relação de equivalência entre o dano e sua reparação, em especial, pela incerteza em definir qual a natureza do interesse que se pretende tutelar, bem como a função que se pretende atribuir à indenização.

Por conseguinte, há a necessidade de suplantar a clássica, porém ultrapassada, dicotomia entre danos morais e danos materiais no âmbito da proteção extrapatrimonial dos interesses coletivos em sentido amplo, sob pena de subutilização dessa importante ferramenta de controle de atos ilícitos no âmbito de uma nova perspectiva de direito plural. ${ }^{26}$

\section{CONCLUSÃo}

Atualmente, em tempos em que o cidadão se preocupa muito mais com o efeito coercitivo da decisão judicial e do que com a lei, como se esta precisasse

\footnotetext{
${ }^{24}$ BARBOSA, Fernanda ; MULTEDO, Renata. Danos Extrapatrimoniais Coletivos. Revista de Direito do Consumidor. São Paulo, ano 23, vol. 93, maio-junho/2014, p. 38-39.

${ }^{25}$ Ibid., p. 41-42.

${ }^{26}$ Ibid., p. 43-44.
} 
sempre ser infirmada em sua validade por um juiz ou Tribunal, o Código de Defesa do Consumidor (Lei 8.078/90) conserva seu status de norma de ordem pública e interesse social, pois esteve sempre na vanguarda e foi a porta de entrada para algumas das principais transformações pelas quais o direito brasileiro vem passando nas últimas décadas, o que gera segurança e estabilidade no âmbito das relações de consumo e vai além.

A previsão de uma vasta tutela material de direitos é blindada por sua base processual extremamente eficaz, concedendo ao consumidor individual e, principalmente, àquele concebido em sua feição coletiva, uma via democrática de acesso ao Judiciário, não como única expressão de participação política (o diálogo permanente nas políticas públicas para as relações de consumo e a articulação associativa nas convenções coletivas de consumo também cumprem este papel), mas essa abertura processual é a que melhor define o conceito de solidariedade para o direito.

Nesse sentido, o presente trabalho demonstrou que a proteção contratual dispensada ao consumidor será instrumentalizada não apenas na forma tradicional, individualmente pulverizada, caracterizada por sua lentidão, formalismo, ineficácia e alto custo. Identificou-se uma verdadeira mudança de paradigmas no processo civil, a partir de sua vertente coletiva, reencontrando a sua finalidade instrumental, em que não mais seria compreendido como um fim em si mesmo, porém como um mecanismo estatal capaz de propiciar aos jurisdicionados o exercício de sua cidadania e o sentimento de segurança jurídica, pois o Estado acenará para os sujeitos da relação de consumo, consolidando sua presença no mercado, pela entrega da prestação jurisdicional de maneira célere e não menos eficaz.

Por derradeiro, conclui-se que as duas modalidades de ações coletivas de controle contratual analisadas no presente artigo: a) ação declaratória de nulidade de contratual e b) ação constitutiva de revisão contratual com possibilidade de cumulação de pedidos condenatórios e/ou cominatórios vão ao encontro de uma nova dimensão plural do Direito das Relações de Consumo, pois permitem que o dirigismo contratual da lei tenha, na tutela transindividual de interesses do consumidor, melhores condições de influir na difusão de deveres éticos ao segmento empresarial, aperfeiçoando a expressão da vontade legítima do consumidor, garantindo o acesso à informação clara e qualificada quanto ao alcance das obrigações contratuais e resguardando a satisfação do interesse social inerente à realização do negócio jurídico em si. 


\section{REFERÊNCIAS}

BARBOSA, Fernanda; MULTEDO, Renata. Danos Extrapatrimoniais Coletivos. Revista de Direito do Consumidor, São Paulo, ano 23, v. 93, maio/junho 2014.

BENJAMIN, Antônio Herman; MARQUES, Claudia Lima. Extrato do Relatório-Geral da Comissão de Juristas do Senado Federal para atualização do Código de Defesa do Consumidor. Revista de Direito do Consumidor, São Paulo, ano 23, v. 93, maio/ junho 2014.

BENJAMIN, Antonio Herman V.; MARQUES, Claudia Lima; BESSA, Leonardo Roscoe. Manual de Direito do Consumidor. 7.ed.rev., atual. e ampl. São Paulo: Revista dos Tribunais, 2016.

BRASIL. Lei $\mathrm{n}^{\circ}$ 8.078, de 11 de setembro de 1990. Código de Defesa do Consumidor. Diário Oficial [da] República Federativa do Brasil, Brasília, 12 set. 1990. Disponível em: <http://www.planalto.gov.br/ccivil_03/Leis/L8078.htm>. Acesso em: 22 fev. 2018.

BRASIL. Lei $\mathrm{n}^{\mathrm{o}}$ 10.406, de 10 de janeiro de 2002. Código Civil. Diário Oficial [da] República Federativa do Brasil, Brasília, 11 jan. 2002. Disponível em: <http://www. planalto.gov.br/CCivil_03/leis/2002/L10406.htm >. Acesso em: 22 fev. 2018.

BRASIL. Lei ${ }^{0} 7.347$, de 24 de julho de 1985. Lei de Ação Civil Pública. Diário Oficial [da] República Federativa do Brasil, Brasília, 25 jul. 1985. Disponível em: $<$ http://www.planalto.gov.br/CCivil_03/leis/L7347orig.htm>. Acesso em: 22 fev. 2018.

BRASIL. Superior Tribunal de Justiça. Recurso especial no 98673/SP, Relator: Min. Luiz Vicente Cernicchiaro, 1997. Jusbrasil. Disponível em: < https://stj.jusbrasil. com.br/jurisprudencia/534682/recurso-especial-resp-98673-sp-1996-0038483-5>. Acesso em: 10 mar. 2017.

BRASIL. Superior Tribunal de Justiça. Recurso especial n $177018 /$ MG, Relator: Min. Luiz Vicente Cernicchiaro, 1998. Jusbrasil. Disponível em: < https://stj.jusbrasil. com.br/jurisprudencia/486478/recurso-especial-resp-177018-mg-1998-0041148-8>. Acesso em: 10 mar. 2017. 
BRASIL. Superior Tribunal de Justiça. Recurso especial no 292942/MG, Relator: Min. Sálvio de Figueiredo Teixeira, 2001. Jusbrasil. Disponível em: < https://stj.jusbrasil. com.br/jurisprudencia/313473/recurso-especial-resp-292942-mg-2000-0133343-7>. Acesso em: 10 mar. 2017.

BUJOSA VADELL, Lorenzo. Coautoria en Manual Básico de Protección de los Consumidores y Usuários. Salamanca: Caja Duero, 2006.

DIDIER JUNIOR, Fredie; ZANETI JUNIOR, Hermes. Curso de Direito Processual Civil: processo coletivo. 4. ed. Salvador: JusPodium, 2009.

MARQUES, Claudia Lima. Os contratos no Código de Defesa do Consumidor. 3. ed. São Paulo: Revista dos Tribunais, 1999.

MARQUES, Claudia Lima. Contratos no Código de Defesa do Consumidor: o novo regime das relações contratuais. 8. ed., rev., atual., e ampl. São Paulo: Revista dos Tribunais, 2016.

REYES LÓPEZ, Maria José. Manual de Derecho Privado de Consumo. Madrid: La Ley, 2009.

SÁNCHEZ BARRIOS, Maria Inmaculada. El ejercicio de la "acción de cesación" en defensa de los consumidores y usuários. In: SÁNCHEZ BARRIOS, Maria Inmaculada (direción). Estudios sobre consumo. Valencia: Tirant lo Blanch, 2012.

VERBICARO, Dennis. Consumer new civil-instrumental identity based on the brazilian consumer policy. In: MARQUES, Claudia Lima; PEARSON, Gail; RAMOS, Fabiana (editors). Consumer protection: current challenges and perspectives. Porto Alegre: Orquestra, 2017.

Recebido em: 11 de outubro de 2017 Aceito em: 24 de julbo de 2018 